should work hand in hand to aid one another in the supreme object of education. A beginning in that direction has been made in the United States and in some towns in England, where the young are taught in the lecture theatre and are then conducted by the teacher to the section of the museum dealing with the subject of the discourse. In this way the young are familiarised with the objects and uses of museums, to which they will surely more readily return in after life, and in the development of which they will take a keener interest than they do at present.

R. F. S.

\section{DR. FRANK McCLEAN, F.R.S.}

I N Dr. Frank McClean astronomy has not only lost one of her most devoted and painstaking followers, but a generous benefactor that can ill be spared, especially in this country. His death came as a surprise to most of his friends, for, although it was known that his increasing years were beginning to tell on his general activity, it was thought that there was still much work left in him. Unfortunately, however, this was not to be, for, at the latter end of his usual trip on the Continent, he was taken ill at Brussels, and very shortly afterwards passed away on November 8 at the age of sixty-seven, surrounded by members of his family.

Dr. McClean was the son of the late distinguished engineer, Mr. J. R. McClean, F.R.S., and was born in 1837. After the completion of his education at Westminster, the College, Glasgow, and Trinity College, Cambridge, of which he was a scholar, graduating in 1859 as a wrangler, he took up the profession of his father, and became apprenticed in the same year to Sir John Hawkshaw; three years later he was taken into partnership in the firm of Messrs. McClean and Stileman.

Up to the year 1870 his energy was directed to engineering matters, but retiring from his profession, he devoted the remaining years of his life to spectroscopic researches in connection with the sun and stars. The success which rewarded his endeavours is best shown by the numerous important papers which he communicated to the Royal Society and Royal Astronomical Society, and by the fact that the council of the latter society awarded him, in I899, the gold medal, their highest honour for astronomical research. The crowning work, which he fortunately completed, and with which his name will always be associated, was the conception and carrying out of the great spectroscopic survey of the brighter stars over the whole celestial sphere.

$\mathrm{He}$ commenced his spectroscopic work with several important researches, all of which were carried out with zeal, patience, and thoroughness; these were naturally closely allied, in fact preliminary steps, to the great work to which he later devoted his energies. The first of these dealt with the photography of metallic spectra by means of an induction spark, after which he turned his attention to the nearest star, the sun, and made an elaborate series of comparative photographs of the spectra at high and low altitudes. An account of this, accompanied by a beautiful atlas of plates, was submitted in 1890 to the Royal Astronomical Society. The high sun spectrum was taken as far as possible when the sun's altitude was more than $45^{\circ}$, and the low sun when it was under $7 \frac{1}{2}^{\circ}$, so that the depth of atmosphere traversed was in the proportion of one to five respectively. For securing these photographs he employed a fixed heliostat to reflect the solar light into a telescope fixed parallel to the polar axis, in conjunction with a spectroscope in which was used a large Rowland plane grating.

$$
\text { NO. I829, VOL. 7I] }
$$

The investigation brought out in a striking manner the different effects of atmospheric absorption in the solar spectrum, and put one on a firmer footing as regards the variations due to atmospheric influences.

After the publication of these results, McClean turned his attention again to terrestrial spectra, and made a minute study of the comparative photographic spectra of the sun and metals. The first results were connected with the spectra of the gold and iron groups of metals. These spectra were collated by means of their common air lines with the iron spectrum, and so by means of the iron lines with the solar spectrum. In the gold group he found many lines due to these metals which up to that time had not been observed, and he also remarked some curious coincidences that existed between the air lines in the metallic spectra and lines in the solar spectrum. That he had in his mind the eventual spectroscopic study of the heavenly bodies is shown even in his brief accounts of these experiments, for in one case he writes, "the spectra of the metals appear to me to be fairly within the scope of astronomy, as our knowledge of them forms the basis of any knowledge we possess of the composition of the heavenly bodies."

At the end of $189 \mathrm{I}$ he published another set of comparative spectra of the sun and metals. The two series consisted of six sections, corresponding to six sections of Angstrom's chart; they were as follows :-

Section i. contained the spectra of the sun, iron, platinum, iridium, osmium, palladium, rhodium, ruthenium, gold, and silver. The last eight constitute the platinum group of metals.

Section ii. contained the spectra of the sun, iron, manganese, cobalt, nickel, chromium, aluminium, and copper. These seven metals constitute the iron copper group.

Throughout McClean's scientific career his greatest work was undoubtedly the spectroscopic survey of every star brighter than $3^{\frac{1}{2}}$ magnitudes scattered throughout the whole celestial sphere.

Such a programme seemed large for one man to tackle single-handed, but McClean was equal to the occasion, and succeeded not only in accomplishing it, but in discussing and publishing the results.

For the northern stars the photographs were secured at his home, Rusthall House, Tunbridge Wells. The instrument employed was a photographic telescope having an object glass of twelve inches diameter, and carrying an objective prism of the same aperture, with a refracting angle of $20^{\circ}$.

To secure the southern stars McClean worked at the Cape of Good Hope from May to November, 1897 . $\mathrm{He}$ took with him the prism he had already used for the northern work, and fixed it in front of the object glass of the well-known Cape astrographic instrument, which had been placed at his disposal by Sir David Gill. Both series of photographs were thus secured with practically identical instruments, the advantage of which it is difficult to overestimate.

Space does not permit, nor is it here necessary, to enumerate at any length the results of such a farreaching research, which were so ably discussed, and received such high praise. Mention, however, may be made of the originality he displayed in referring the stars to galactic latitude and longitude, instead of employing the usual system of right ascension and declination. The celestial sphere he divided into four equal areas by drawing a circle at a radius of $60^{\circ}$ from each galactic pole. By means of a great circle passing through the galactic poles, he cut the sphere into two halves, so that each of the four areas was again equally divided. This apparently simple portioning of the heavens was amply rewarded. 
In discussing the relation of special type stars to the Galaxy, one of the chief facts that made itself at once apparent was that "Helium" stars were not indiscriminately scattered over the heavens like the solar or other type stars, but were more thickly concentrated in the two zones north and south of the galactic equator. In addition, among many other outcomes of this survey was the discovery of oxygen in the spectrum of $\beta$ Crucis, and in the helium stars generally.

The energy and stamina displayed by McClean in all his work will be best understood when it is mentioned that he employed no assistants. In his laboratory he was the sole operator, and in the observatory at night every manipulation was accomplished by his own hands. To quote the words of the president of the Royal Astronomical Society when presenting him with the gold medal, ".... it was his eye that measured the lines, and his was the pen that worked out the calculations. Need I add more to prove that what Mr. McClean's hand had found to do he did with all his might?"

Turning now from this very brief and incomplete summary of McClean's scientific work, reference must be made to his generosity in presenting munificent gifts for the advancement of astronomy. Being a worker himself, he was in a position to know in what direction monetary aid could be best employed. As the founder of the Isaac Newton studentships at Cambridge University, requiring an endowment of $I_{5}, 000 l_{\text {. }}$, he rendered a service to astronomical science which it would be hard to overestimate, and the results that will accrue from it will, we hope, be a fitting memorial to his name.

Not content with providing in this way the means by which the study of astronomy will be encouraged, he presented the Cape Observatory, ten years ago, with a large telescope, fittings, and dome, with all the latest improvements, to accomplish work which otherwise would have been delayed possibly for many years. He saw at once the field that was open and the advance that was possible if the southern heavens were surveyed by a prismatic camera of large dimensions, and he took this opportunity to supply the necessary means.

The fact that Sir David Gill in his recent report for the year 1903 writes, "The Zeiss prism is a very perfect and transparent piece of glass, and I have no doubt that its performance will do credit to the fame of its makers. The observatory is indebted to $\mathrm{Mr}$. McClean for this splendid gift, as also for the costly alterations to the spectroscope," shows that McClean's original gift has been greatly increased. As the inauguration of the "Victoria" telescope forms an epoch in the history of the Cape Observatory, may the results obtained with it play a like rôle in the advancement of stellar spectroscopy for the southern hemisphere.

McClean was elected a fellow of the Royal Society in 1895 ; the university of Glasgow conferred on him the honorary degree of LL.D., while, as previously mentioned, he obtained the gold medal of the Royal Astronomical Society.

In 1865 he married Ellen, the daughter of Mr. John Greg, of Escowbeck, Lancaster, who now mourns with her three sons and two daughters his loss. They are not, however, alone in their grief, for his death is deeply felt by a large circle of friends, among whom are many astronomical colleagues who will miss his familiar face.

The funeral, which took place on Friday last, was attended by representatives from many societies and institutions, among which may be mentioned the Cambridge University, the Royal Society, the Royal
Astronomical Society, the British Association, the Institution of Civil Engineers, Greenwich Observatory, Solar Physics Observatory, and the Cambridge University Observatory.

W. J. S. L.

\section{NOTES.}

THE seventieth birthday of Prof. G. H. Quincke, the doyen of German physicists, will be celebrated at Heidelberg on Saturday next, November ig. Prof. Quincke's laboratory formed the subject of a contribution to our series of scientific centres in NATURE of April 24, 1902, and his portrait was reproduced in the article. Reference was then made to the admirable manner in which the laboratories at Heidelberg are arranged, and the many ingenious devices to be found in them, as well as to some of the investigations carried on. It is therefore unnecessary to attempt to describe again the results of Prof. Quincke's uninterrupted work in physical research for nearly half a century. Among Prof. Quincke's many pupils have been Prof. Lenard (Kiel), Prof. Braun (Strassburg), Prof. W. König (Greifswald), Profs. Elster and Geitel (Wolfenbüttel), the late Prof. Willard Gibbs, Prof. Michelson, Dr. J. T. Bottomley, F.R.S., Dr. J. McCrae (Glasgow), \&c. ; a complete list would include many other English and American students. To celebrate the occasion of Prof. Quincke's seventieth birthday, a committee, with Prof. Kohlrausch (Berlin) as president and Dr. R. H. Weber (Heidelberg) as secretary, has arranged for the presentation of a large and handsome album containing the autograph photographs of many of the leading physicists of all nationalities and of Prof. Quincke's former pupils. A convincing testimony of the high value set on Prof. Quincke's work in this country is supplied not only by the lists of universities and learned societies which have conferred their honours on him, but aiso by the fact that among the English physicists and personal friends who have contributed photographs are Lord Kelvin, Lord Rayleigh, Sir W. Huggins, Sir W. Ramsay, Sir H. E. Roscoe, Sir N. Lockyer, Sir W. H. Preece, Prof. J. J. Thomson, Sir A. Rücker, Prof. J. Larmor, Prof. J. A. Ewing, Mr. C. V. Boys, Sir O. Lodge, Prof. J. H. Poynting, Prof. G. Carey Foster, Prof. A. Schuster, Dr. W. N. Shaw, Prof. J. Perry, Prof. R. B. Clifton, Prof. J. G. MacGregor, Prof. J. T. Joly, Prof. G. H. Darwin, Prof. W. G. Adams, Prof. W. M. Hicks, Prof. H. Stroud, Prof A. P. Chattock, Prof. A. S. Herschel, and many others.

THE American Consul at Bermuda describes in a United States Consular Report the steps which have been taken to establish there a biological station which will be to North America what the Naples station is to Europe. For several years American naturalists have carried on investigations of the natural history of the Bermudas and the surrounding sea, and have made efforts to establish a biological station in these islands. Upon the advice of the Royal Society, our Government has given its assent to the project. The Colonial Government has expressed its willingness to purchase the land and erect the building, and grants toward equipment and support of tables have been made by the Royal Society and the Carnegie Institution. Harvard University and New York University, in connection with the Bermuda Natural History Society, have already commenced work in a temporary laboratory close to what will be the permanent quarters of the station, and the United States Government has been asked to give generous support to the station. America has already founded a tropical botanical laboratory in buildings of the Government of Jamaica at

$$
\text { NO. I829, VOL. } 7 \text { I] }
$$

